\title{
Fruit shape and reproductive self and cross compatibility for the performance of fruit set in an andromonoecious species: Xanthoceras sorbifolium Bunge
}

\author{
Qing Wang $^{1,2}$ • Yanzi Huang ${ }^{1}$ - Ziyang Wang ${ }^{1}$ - Yousry A. El-Kassaby ${ }^{2} \cdot$ Wenbin Guan $^{1}$
}

Received: 29 March 2017 /Revised: 24 September 2017 / Accepted: 28 September 2017 / Published online: 14 October 2017

(C) The Author(s) 2017. This article is an open access publication

\begin{abstract}
A replicated $6 \times 6$ complete diallel mating among six fruit shape types of Xanthoceras sorbifolium (yellowhorn), an andromonoecious plant known for its exceedingly low fruit and seed set, was conducted to investigate the species mating system. This mating design was implemented to investigate the relationship between fruit shape type and fruit yield, finding the most productive fruit shape-type matings, and explore maternal and paternal plants spatial arrangements for yield enhancement. The study confirmed the maternal inheritance of fruit shape type, open-pollination often associated with low fruit production, the presence of high inbreeding depression, and differential yield among fruit shape-type matings and directions and identified specific matings between fruit shape types with increased yield potential for the species' commercial production. A high fruit yield planting spatial arrangement of parents is proposed and its pro et contra under openpollinated production mode were discussed.
\end{abstract}

Keywords Xanthoceras sorbifolium · Yellowhorn · Diallel mating design - Mating preference and direction · Fruit shape and yield $\cdot$ Spatial planting arrangement

Communicated by P. Ingvarsson

Yousry A. El-Kassaby

y.el-kassaby@ubc.ca

Wenbin Guan

swlab@bjfu.edu.cn

1 School of Nature Conservation, Beijing Forestry University, Beijing 100083, China

2 Department of Forest and Conservation Sciences, Faculty of Forestry, The University of British Columbia, Vancouver, BC V6T 1Z4, Canada

\section{Introduction}

Andromonoecious species have received increased attention for their peculiar reproductive schemes in which plants produce both perfect and staminate flowers (Bawa et al. 1982; Miedaner and Geiger 2015; Renner 2014). This peculiar reproductive system exists in approximately 4000 species, representing 2\% of flowering plants (Cohen and Dukas 1990). Xanthoceras sorbifolium Bunge (Sapindaceae), known as yellowhorn or wen guan guo, is an andromonoecious oilseed tree species that is widely distributed in northern China (Fu et al. 2008). In this species, plants produce a large number of male and a limited number hermaphrodite flowers (Zhou and $\mathrm{Fu} 2010$ ). As anthers of the hermaphrodite flowers do not dehisce at anthesis, thus, they are functionally female (Zhou and Liu 2012). Seeds of this species contain copious amount of unsaturated fatty acids that have dietary, medicinal, and industrial uses (Zhang et al. 2010). Additionally, yellowhorn husk's extract has cytotoxic effect toward various human cancer cell lines (Chan and Mak 2006), and its wood triterpenes have shown inhibitory activity against HIV-1 protease (Ma et al. 2004), hence the species economic potential. However, yellowhorn suffers from extremely low fruit yield and is dubbed as "the tree of thousand flowers but one fruit" (Ding and Ao 2008).

Tree breeding is a long-term endeavor requiring sustained scientific, financial, and administrative commitment (ElKassaby et al. 2015). Since the primary goal of yellowhorn production is fruit yield, then attributes associated with increased fruit yield would be of value for the phenotypic selection of suitable parental candidates. Fruit shape (length and width) of yellowhorn is reported to be highly correlated with fruit yield (Chai et al. 2013) and as in many species [e.g., Douglas-fir (El-Kassaby and Cook 1994); apple (Stajnko et al. 2009); pear (Canli and Pektas 2015)] is under strong 
genetic control [i.e., high heritability (El-Kassaby 1995; Grandillo et al. 1999; Serquen et al. 1997; Tan et al. 2015)]. The observed high heritability for fruit shape in other species is attributable to the presence of major genes (Cantín et al. 2010) and strong maternal effect (Zhang et al. 2007). In spite of the reported fruit shape's high heritability, the breeding system and/or its mode of inheritance of yellowhorn have not been determined.

Hand-pollination experiment is one way to determine a species' breeding system and differences among its biological characteristics such as fruit shapes (Zhang et al. 2007). We are aiming at addressing three principal questions: (1) Does fruit shape allow to infer yield potential? (2) Which shape type is best matched with respect to yield aspect? (3) Can we improve the fruit yield under field conditions by various spatial arrangements of maternal and paternal plants?

\section{Materials and methods}

\section{Study area}

Trees of yellowhorn used in this study were growing in an experimental orchard in the Liaoning Institution of Afforestation, Jianping County, Liaoning Province, northeast of China $\left(119^{\circ} 1^{\prime}-120^{\circ} 2^{\prime} \mathrm{E}, 40^{\circ} 17^{\prime}-42^{\circ} 21^{\prime} \mathrm{N}\right)$ containing a 33-year-old "Superior Tree Clone Test Garden" representing most of the yellowhorn genetic resources in China. The study site has a typical transition climate from north temperate maritime monsoon to continental, semi-humid and semi-arid or drought-prone with average temperature of $7.8^{\circ} \mathrm{C}$ and annual precipitation of $614.7 \mathrm{~mm}$ which is concentrated in $6 \sim 8$-month period with a 120 to 155 frost-free day period. Soil is barren with average organic matter content of $1 \%$. Most of the organic matter is fresh or semi-humic organic matter lacking $\mathrm{P}$ and $\mathrm{N}$, with less potassium and zinc and low utilization efficiency.

\section{Experimental design}

Over a 3-year observation period (data not given), we noticed that the fruit shape on each tree was constant, accordingly, we classified the fruit shape based on their length $(\mathrm{cm})$ and width $(\mathrm{cm})$ measurements into six fruit shape types (Table 1 and Fig. 1). To augment the fruit shape-type description, we also estimated the coefficient of roundness/eccentricity (fruit length/fruit width) (Table 1). On May 2014, we conducted a $6 \times 6$ diallel cross control pollination based on the identified six different fruit shape types, with three replications (groups) performed on 18 parents (i.e., three genotypes/fruit shape type). We divided the 18 parents to three groups namely, A, $\mathrm{B}$, and $\mathrm{C}$, each containing the six fruit shape types and structured the mating within each group combinations (i.e., $\mathrm{A} \times \mathrm{A}$, $\mathrm{B} \times \mathrm{B}$, and $\mathrm{C} \times \mathrm{C}$ ) (Fig. 2). For each inflorescence, eight

Table 1 The yellowhorn fruit shape-type classification along with coefficient of roundness (length/width). (mean \pm SE)

\begin{tabular}{clll}
\hline $\begin{array}{l}\text { Fruit } \\
\text { shape type }\end{array}$ & $\begin{array}{l}\text { Average } \\
\text { length }(\mathrm{cm})\end{array}$ & $\begin{array}{l}\text { Average } \\
\text { width }(\mathrm{cm})\end{array}$ & $\begin{array}{l}\text { Coefficient of } \\
\text { roundness }\end{array}$ \\
\hline 1 & $6.64 \pm 0.10$ & $4.91 \pm 0.07$ & 1.35 \\
2 & $5.90 \pm 0.04$ & $5.25 \pm 0.02$ & 1.12 \\
3 & $6.83 \pm 0.08$ & $5.92 \pm 0.06$ & 1.15 \\
4 & $4.85 \pm 0.06$ & $4.62 \pm 0.04$ & 1.05 \\
5 & $6.47 \pm 0.10$ & $5.24 \pm 0.08$ & 1.23 \\
6 & $5.42 \pm 0.04$ & $4.94 \pm 0.04$ & 1.10 \\
\hline
\end{tabular}

bisexual flowers were retained and the remaining flowers were removed. Additionally, we also selected six inflorescences (eight bisexual flowers on each inflorescence) on each maternal tree for open-pollination and used then for comparing wind vs. controlled pollination.

\section{Controlled pollination}

Prior to anthesis, bisexual (hermaphrodite) and male flowers were selected from the inflorescences and the inflorescence of bisexual flowers were bagged followed by the removal of any opening flowers. The developmental flowering state in the pollination bags were observed daily in the morning and afternoon, and receptivity time of each bisexual flower was recorded, and any open unisexual (male) flowers were directly removed and

(1)

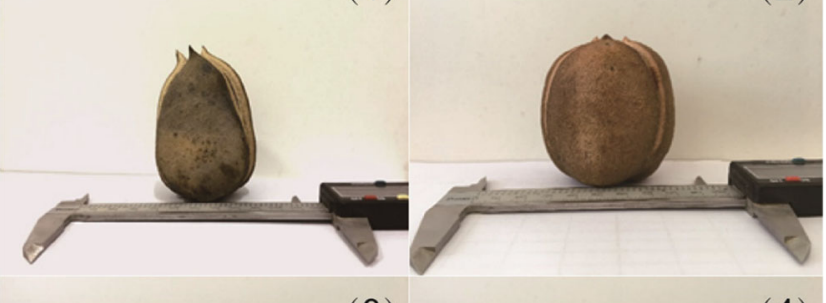

(3)

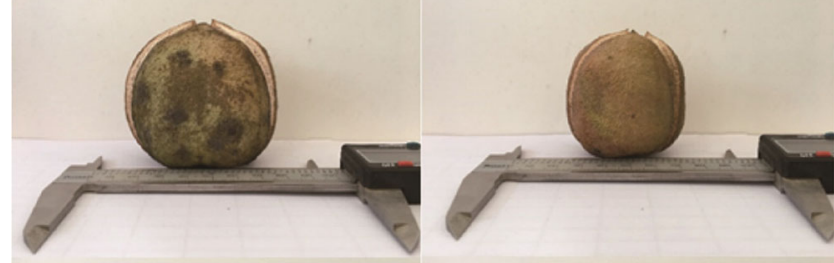

(5)

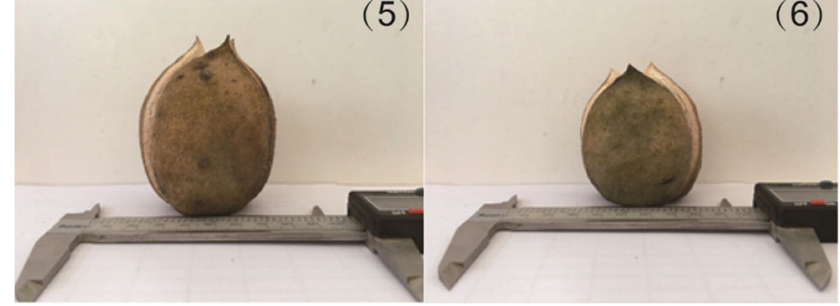

Fig. 1 The yellowhorn six fruit shape types as classified by length and width (see Table 1 for the corresponding numbers) 
Fig. 2 Schematic of the $6 \times 6$ diallel cross control pollination experiment showing mating combinations within the three (A, $\mathrm{B}$, and C) groups. Columns and rows stand for pollen donor and pollen receptor, respectively. Numbers (1-6) within each group represent the six different fruit shape types

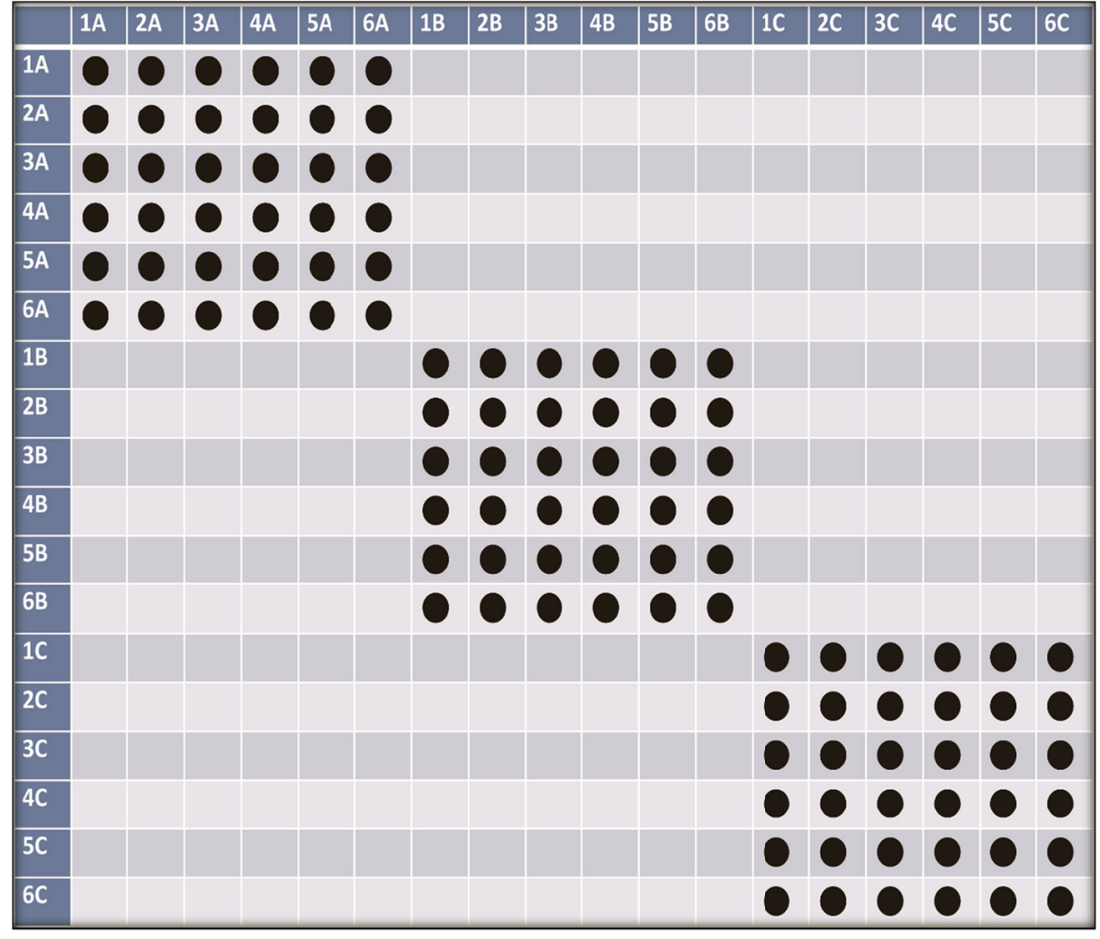

recorded. Open bisexual flowers were pollinated using more than three completely developed stamens from male flowers and the presence of pollen on the stigma was noted. This process was repeated on subsequent bagged open bisexual flowers. After eight bisexual flowers were successfully pollinated, other flowers were removed and the pollination bags were removed 2-4 days after the pollination of the last flower.

\section{Data collection and analysis}

After harvest (mid-August), fruit length $(\mathrm{cm})$ and width $(\mathrm{cm})$ measurements data were collected to verify that shape type classified is similar to that of the maternal parents. Additionally, fruit, seed, and shell weights (in grams) and fruit and seed number per inflorescence as well as single seed weight (in grams) were measured for all controlled crosses as well as the open-pollination. To determine the differences among the six fruit shape types as well as that from openpollination, we performed analysis of variance and multiple comparison of means using SPSS 20.0 (Kirkpatrick and Feeney 2012). Levene's test was used to verify the homogeneity of variance among the studied attributes, and logarithmic transformation was required for fruit length and width, fruit seed and shell weight, and fruit and seed number per inflorescence. Nonparametric multiple comparison among the yellowhorn matings response to six mother tree's fruit type using Wilcoxon rank sum test and Kruskal-Wallis test using "car," "rcompanion," and "multcompView" were carried out in R package (R Core Team 2013).

\section{Results}

A total of 216 inflorescences with 1728 bisexual flowers (eight flowers in each inflorescence) were included in the pollination experiment. We noticed that most flowers open during the morning and the optimum time for pollination of bisexual flowers is during the first day of anthesis. We harvested 81 of 108 fruit setting inflorescences (fruit set $=75 \%$ ) and 256 fruits (average $=3.2$ fruits/inflorescence). While in the open-pollination, 98 of 108 fruit setting inflorescences (fruit set $=91 \%$ ) and 175 fruits (average $=1.8$ fruits/inflorescence) were harvested. In addition to the commonly used fruit shape-type description, we have included the coefficient of roundness/eccentricity (fruit length/fruit width) to augment our description (Table 1). This index information has obscured fruit size differences as ratio indices tend to distill the information to a single value. For example, fruit shape types 2, 3, and 6 produced similar eccentricity indices of 1.12, 1.15, and 1.10, respectively; however, they exhibited intermediate, large, and small fruit sizes; thus, we used the commonly accepted fruit shape-type description (Table 1 and Fig. 1).

\section{Comparison among open-, cross-, and self-pollination}

Without exception, all self-pollination matings produced the lowest weighted average values for the six studied attributes $(1.50,21.51 \mathrm{~g}, 10.19 \mathrm{~g}, 11.32 \mathrm{~g}, 14.00$, and $0.870 \mathrm{~g}$ for fruit number, fruit weight, shell weight, seed weight, seed number per inflorescences, and single seed weight, respectively, see Table 2). In fact, five out of the six self-pollination crosses 
have failed to produce any products, highlighting the detrimental effect of selfing (Table 2).

Across the six studied attributes, open-pollination produced higher weighted averages than their self-pollination counterparts (1.78 vs. $1.50,59.78$ vs. $21.51 \mathrm{~g}, 28.44$ vs. 10.19 g, 31.34 vs. 11.32 g, 29.54 vs. 14.00 , and 1.10 vs. $0.87 \mathrm{~g}$, for fruit number, fruit, shell, and seed weight, seed number, and single seed weight, respectively) (Table 2). Generally, open-pollination produced lower attributes' weighted averages comparing to cross-pollination; however, exceptions were observed for shell weight ( $93: 28.44$ vs. $20.56 \mathrm{~g}$ ), seed weight ( $\$ 1: 31.34$ vs. $25.48 \mathrm{~g}$ vs. +6 : $27.47 \mathrm{~g}$ ), seed number ( $91: 29.54$ vs. 18.87), and single seed weight ( 95 and $6: 1.10$ vs. $0.88 \mathrm{~g}$ vs. ${ }^{3} 1,3,4$, and 5: 1.04 , $1.05,1.06$, and $1.02 \mathrm{~g}$, respectively) (Table 2).

Open-pollination mating results are of scientific and practical significance as they provide insight on the most practical production mode where the different fruit types act as recipients for pollen from other fruit types. As females, fruit shape types 2,3 , and 5 produced significantly higher weighted averages than the other fruit type shapes for all attributes except that of single seed weight, making them good candidate for open-pollination production options (Table 2; Fig. 3). As high single seed weight is directly associated with oil yield, fruit shape type 1 ranked highest among the other fruit shapes but was low for average fruit weight and seed weight (Fig. 3).

\section{Comparison among the cross-pollination types is best assessed based on}

\section{General compatibility}

For each studied attribute, across male and female, weighted averages were estimated and used to assess each fruit shapetype universal contribution as a pollen donor to or pollen recipient from the other fruit shape types (general compatibility). Generally, when fruit shape types 2 and 3 participated as pollen recipients (i.e., females), they were among the best producers (우2: 3.70, $138.175 \mathrm{~g}, 55.26 \mathrm{~g}, 82.90 \mathrm{~g}, 74.17$, and $1.12 \mathrm{~g}$ for fruit number (\#1 rank), fruit weight (\#1 rank), shell weight (\#2 rank), seed weight (\#1 rank), seed number (\#1 rank) per inflorescence, and single seed weight (\#3 rank), respectively, and 우 3: $3.50,130.38 \mathrm{~g}, 61.41 \mathrm{~g}, 68.97 \mathrm{~g}, 62.53$ and $1.18 \mathrm{~g}$ for fruit number (\#2 rank), fruit weight (\#2 rank), shell weight (\#1 rank), seed weight (\#2 rank), seed number (\#3 rank) per inflorescences, and single seed weight (\#2 rank), respectively) (Table 2). When the different fruit shape types participated as pollen donors (i.e., males), fruit type 1, 3, and 4 were among the best producers ( $\mathrm{\jmath} 1: 3.73,133.51 \mathrm{~g}, 57.91 \mathrm{~g}, 75.59 \mathrm{~g}, 72.47$, and $1.04 \mathrm{~g}$ for fruit number (\#1 rank), fruit weight (\#1 rank), shell weight (\#1 rank), seed weight (\#1 rank), seed number (\#1 rank) per inflorescences, and single seed weight (\#6 rank), respectively, and 3 : $3.42,104.99 \mathrm{~g}, 46.14 \mathrm{~g}, 58.85 \mathrm{~g}, 58.25$, and $1.05 \mathrm{~g}$ for fruit number (\#2 rank), fruit weight (\#2 rank), shell weight (\#2 rank), seed weight (\#2 rank), seed number (\#2 rank) per inflorescences, and single seed weight (\#5 rank), respectively, ơ $4: 3.17,99.37 \mathrm{~g}, 44.38 \mathrm{~g}, 55.00 \mathrm{~g}, 54.00$, and $1.06 \mathrm{~g}$ for fruit number (\#3 rank), fruit weight (\#3 rank), shell weight (\#3 rank), seed weight (\#3 rank), seed number (\#3 rank) per inflorescences and single seed weight (\#4 rank), respectively) (Table 2). Only fruit shape type 3 was a good general combiner as female and male.

\section{Specific compatibility}

The highest productive mating (i.e., specific cross) within each attribute's diallel were 4.67, $183.48 \mathrm{~g}, 82.97 \mathrm{~g}$, $106.84 \mathrm{~g}, 92.33$, and $1.47 \mathrm{~g}$ for fruit number $(\$ 2 \times \widehat{\jmath} 1)$, fruit weight $(+2 \times \widehat{\$} 1)$, shell weight $(q 3 \times \widehat{\$} 1)$, seed weight $(\$ 2 \times \delta 1)$, seed number $(+2 \times \widehat{\$} 1)$ per inflorescences, and single seed weight $\left(+1 \times{ }^{\lambda} 2\right)$, respectively (Table 2). Fruit shape types 1 and 2 were repeatedly involved in these high specific compatibility crosses, indicating their potential production under control crossing pollination scenario; however, it should be highlighted that while fruit shape type 1 is showing high productive for specific matings, it has extremely low yield and this counterproductive for oil yield.

\section{Reciprocal crosses comparisons}

Productivity differences between reciprocal crosses reflect the existence of maternal effect and give an insight on the performance of a specific fruit shape type as either male or female. Fruit shape types 2,3 , and 5 produced minimal production differences between their reciprocal crosses when compared with those among the remaining crosses, for example, 0.25 for fruit number (reciprocal crosses between fruit shape 3 and 5), $2.83 \mathrm{~g}$ for fruit weight (reciprocal crosses between fruit shape 3 and 5), 2.03 and $4.65 \mathrm{~g}$ for shell weight (reciprocal crosses between fruit shape 2 and 3, and 3 and 5, respectively), 1.20 and $4.25 \mathrm{~g}$ for seed weight (reciprocal crosses between fruit shape 2 and 3, and 3 and 6, respectively), 11.5 for seed number (fruit shape 2 and 5) per inflorescences, and 0.04, 0.05 for single seed weight (reciprocal crosses between fruit shape 2 and 5 , and 2 and 4, respectively) (Table 2). The small production differences between the reciprocal crosses of fruit shape types 2, 3, and 5 again support their use in an open-pollination production setting.

\section{Discussion}

Yellowhorn is an andromonoecious species; however, practically, it is monoecious as the morphologically hermaphrodite flowers are functional females, and the pollen produced from individual plant male flowers often yields no or substantially 
$\Rightarrow$ 유 =

$\stackrel{8}{\gtrless}$

m m ले त

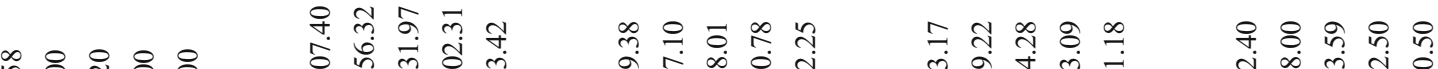

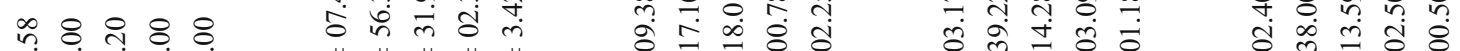

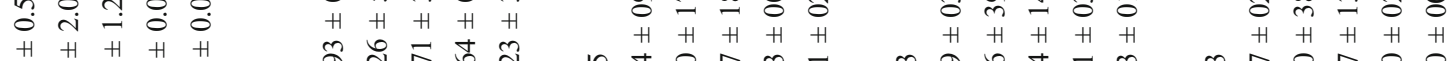

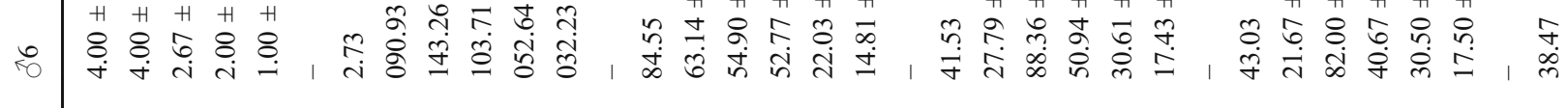

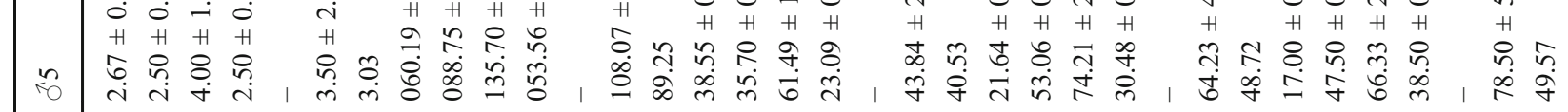

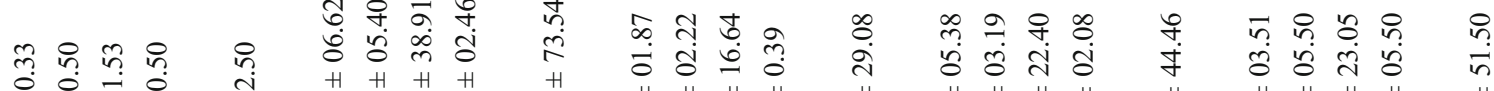

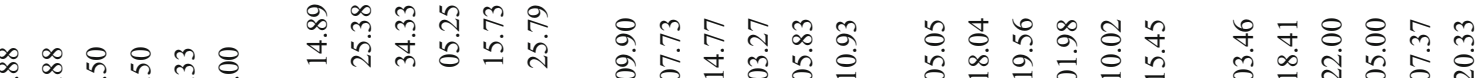

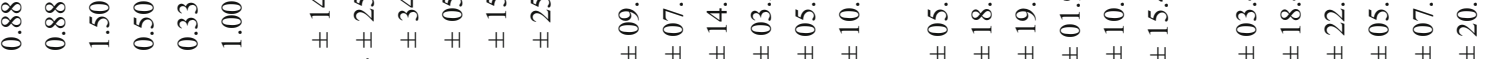

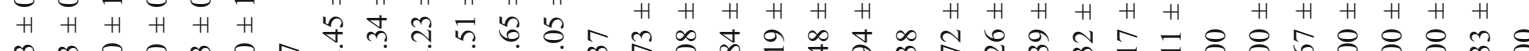

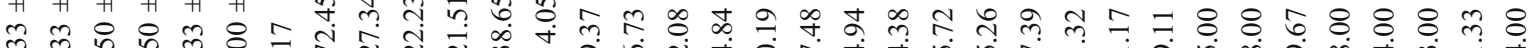
mं mm

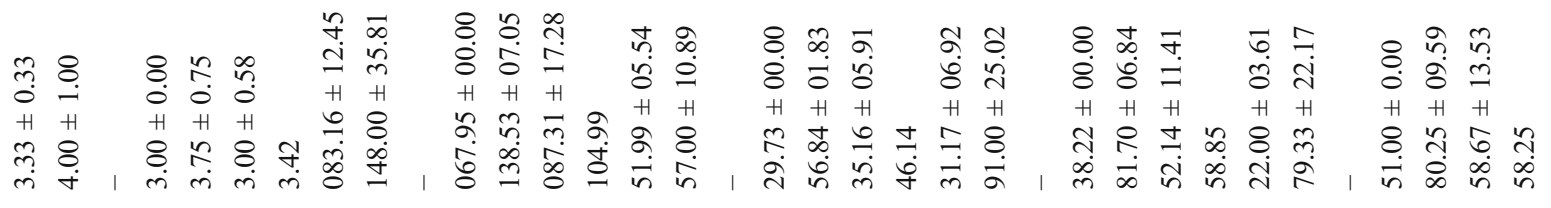

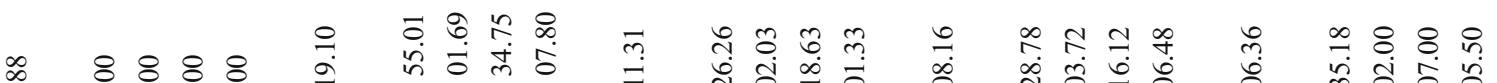

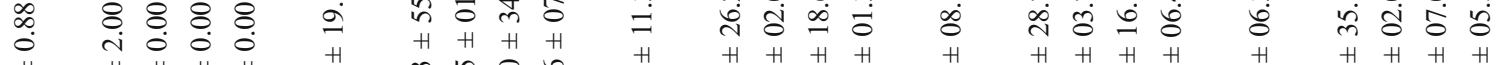
H H H H H

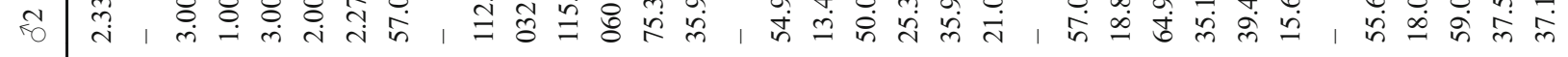

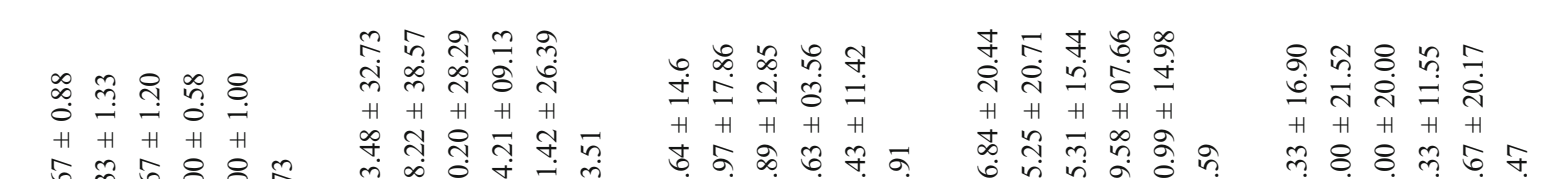
- ,

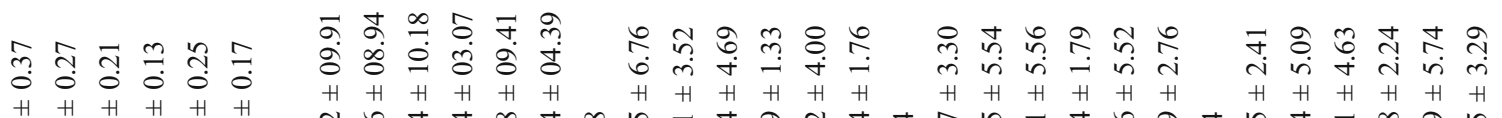

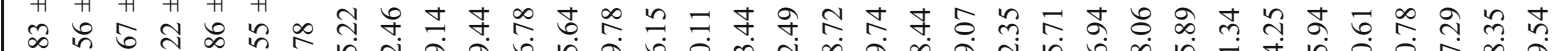

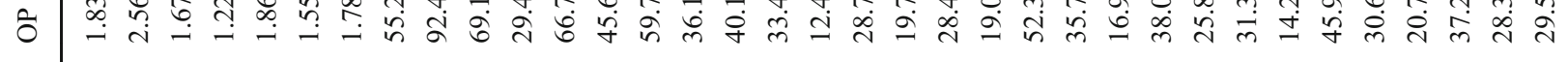

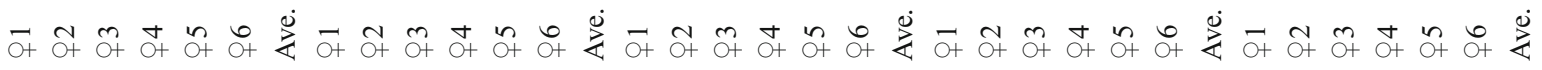

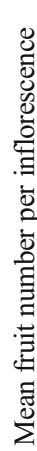
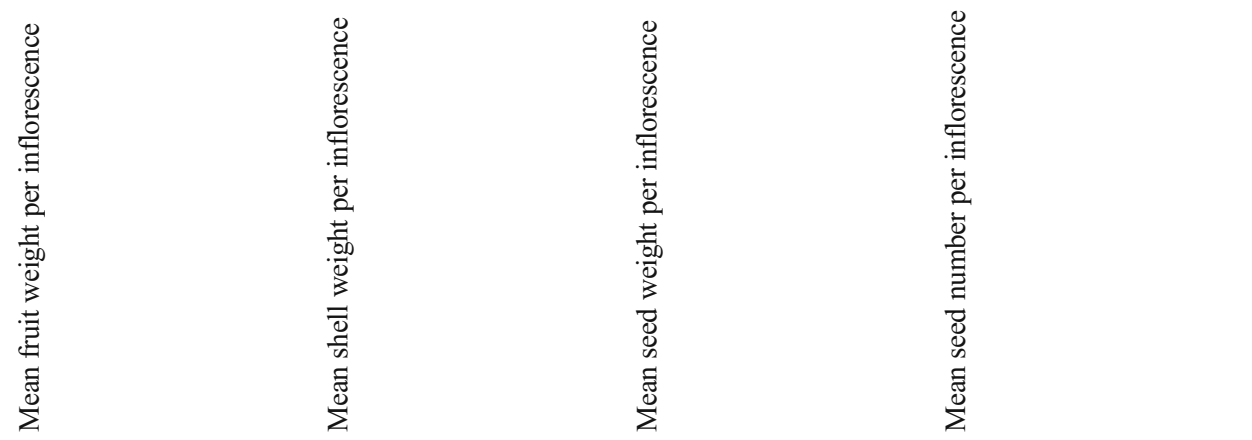


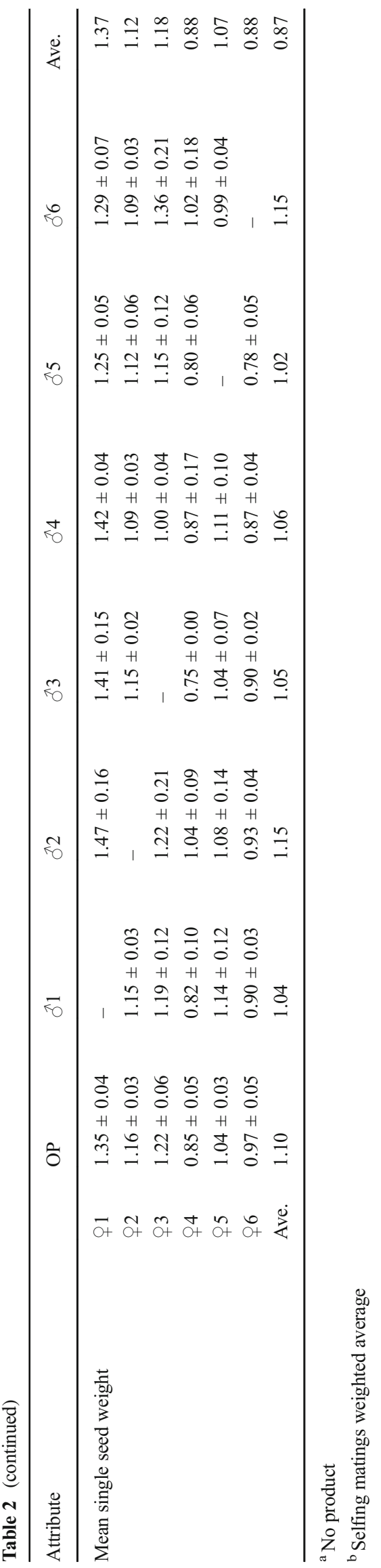

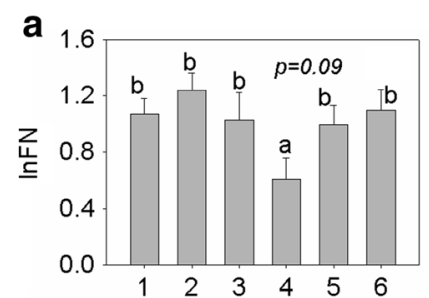
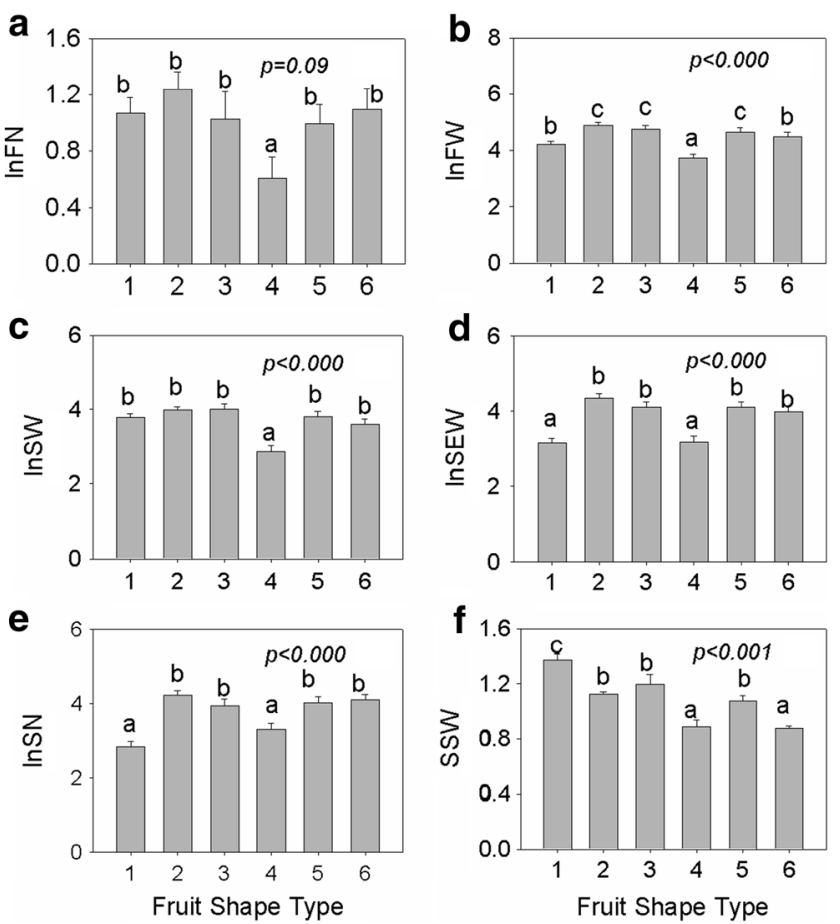

Fig. 3 Variation in mean $( \pm \mathrm{SE})$ for a fruit number $(\operatorname{lnFN})$, b fruit weight $(\ln F W)$, c shell weight $(\operatorname{lnSW})$, d seed weight $(\operatorname{lnSEW})$, e seed number $(\operatorname{lnSN})$, and $\mathbf{f}$ single seed weight (SSW) per individual inflorescence among the yellowhorn matings by six pollen recipients' fruit types

reduced fruit or seed production as demonstrated in the present study (Table 1). It is reported that yellowhorn exhibit lateacting self-incompatibility (LSI) for protecting the species from inbreeding harmful effects reported (Zhou and Zheng 2015). The observed drastic differences in all fruit and seed attributes between selfing and outcrossing matings highlights the impact of inbreeding depression in yellowhorn (Table 2). Selfing resulted in a relatively low fruit set, fruit and shell weight, and seed and fruit number per inflorescences (note: one out of the six possible self-matings produced fruits and seeds) (Table 2). Selfing in yellowhorn may lead to decreasing diversity, furthermore increasing the hazard of sexual recruitment [i.e., reduced mate availability (Bartlewicz et al. 2015)], which constrains the species ability to reproduce sexually (Scobie and Wilcock 2009; Young and Pickup 2010). This is expected as outcrossing species harbor high genetic load and the large body of experimental work provided enough evidence indicating that the superiority of outcrossing offspring (Charlesworth and Charlesworth 1987).

Therefore, improving yellowhorn's fruit and seed yield is rooted in both female and male reproductive success (i.e., fitness). Theoretical sexual selection studies in plants have predicted the presence of conflict between attributes affecting individual or both male and female functions (Bedhomme et al. 2009; Jordan and Connallon 2014); thus, floral traits evolution is expected to mirror the balance between male and female selection forces (Runquist et al. 2017). The allocation of 
Fig. 4 Spatial representation for the possible yellowhorn high yield where fruit shapes 2,3 , and 5 are placed in an alternating rows where each fruit type is flanked by the other two types. (artwork: Q. Wang)
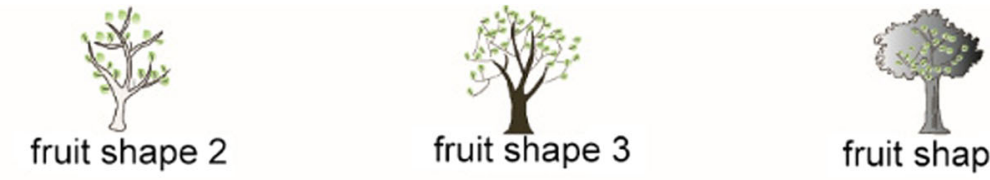

fruit shape 5

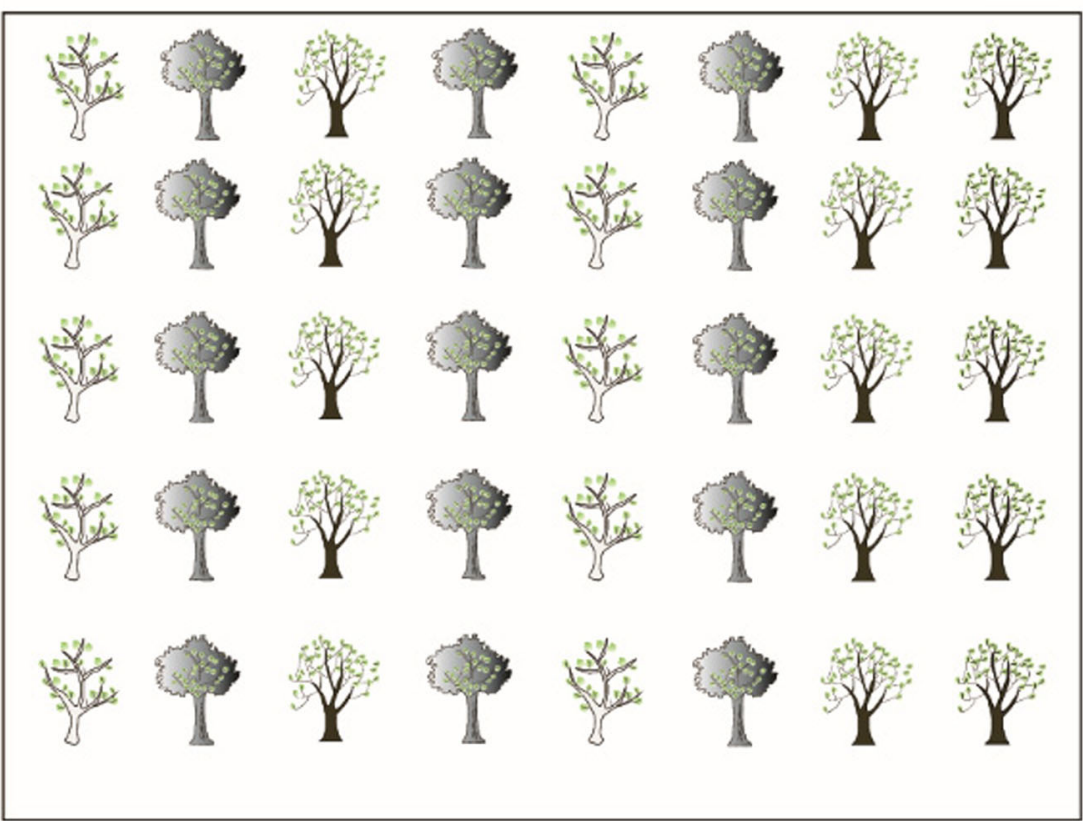

resources between male and female dictates their respective fitness (known as "Bateman's principle" (Bateman 1948)). This is clearly illustrated in outcrossing species, such as yellowhorn, where female fitness is limited by the resources allocated to perfect flowers production (i.e., number of female flowers) whereas the resource allocation to male flowers is expected to have greater fitness as evidence by the substantial amount of pollen produced. Attempts at increasing yellowhorn female fitness were experimentally illustrated through the manual removal of its functional male flowers (Qiao 2009). Furthermore, increasing complete fruit development and seed yield can be accomplished through the manual removal of portion of pollinated female flowers, thus concentrating the resources to the remaining subset (Qiao 2009).

The present study was conducted to address three questions: (1) Does fruit shape allow to infer yield potential? (2) Which shape type is best matched with respect to yield aspect? (3) Can we improve the fruit yield under field conditions by various spatial arrangements of maternal and paternal plants? Here our results demonstrated the maternal effect/inheritance of yellowhorn fruit's attributes, confirming earlier observations on fruit shape type (Chai et al. 2013) and supporting other studies reporting on maternal plant genotype influence on fruit and seed attributes [e.g., Heterosperma pinnatum (Stephenson 1992), tomato (Venable and Burquez 1989), Cucumis melo (Liu et al. 2003), L texensis (Selim 2013)]. The diallel mating scheme used in the present study provided an in depth illustration of the differences among the fruit shape types and their mating combinations (Table 2, Fig. 3).
Significant variation in fruit and seed attributes were observed and highlight the high yield of fruit shape types 2 and 3 which produced the highest fruit number, heaviest fruit seed and shell weight, and the most seed number per inflorescences, making them good candidates for an industrial scale production (Fig. 3). Single seed weight of yellowhorn is a very important economic index in marketing as heavier seeds tend to be more desirable for their high oil yield, reflecting greater differential provision for seed from larger fruit shape type. While fruit shape type 1 had a higher average seed weight, it produced low fruit number and was low in the other fruit traits, making it undesirable for commercial fruit production (Fig. 4).

To address the second question (i.e., which shape type is best matched with respect to yield aspect?), the implemented diallel mating design with its three replications produced striking specific compatibility, and the high morphs diversity among the different fruit shape types cross-pollinations provided a direct method for assessing not only the difference between selfing and outcrossing but also permitted the detection of good general and specific combiners. We identified unique mating direction patterns as some fruit shape type universally performed better as either pollen donor (males) or pollen recipient (females), reflecting their general compatibility. For example, fruit shape types 2 and 3 performed best as females, 1,3 , and 4 as males, and only fruit shape type 3 was good general combiner as female and male. These observations clearly support mixed-fruit shape-type mating in yellowhorn and the diversity among mating indicated that the fruit yield is controlled by the phenotype of both maternal and paternal 
Table 3 Correlation between fruit length and width and yield estimated across the six fruit types $^{1}$

\begin{tabular}{llllll}
\hline Fruit $(\mathrm{cm})$ & Fruit weight $(\mathrm{g})$ & Shell weight $(\mathrm{g})$ & Seed weight $(\mathrm{g})$ & Seed number & Single seed weight $(\mathrm{g})$ \\
\hline Length & $0.449^{* * *}$ & $0.678^{* * *}$ & $0.206^{* * *}$ & $0.048^{* * *}$ & $0.393^{* *}$ \\
Width & $0.638^{* *}$ & $0.599^{* *}$ & $0.430^{* *}$ & $0.159^{* *}$ & $0.199^{* *}$ \\
\hline${ }^{1} N=431$ & & & & \\
${ }^{* *}$ Significant at $p<0.01$ & & & &
\end{tabular}

parents. Similarly, fruit shape types 1 and 2 crosses repeatedly demonstrated high compatibility, indicative of their unique compatibility and making them as good candidates for control crossing (Table 2). Finally, the observed differences between the reciprocal crosses highlight the role of each fruit shape type in the mating as either male or female and their utility in seed production. Drastic and minimal productivity differences were observed between fruit shape types 1 and 26 and those between 2,3 , and 5 crosses, respectively, supports their use in an openpollination production mode. Generally open-pollination produced highly significant correlations between fruit types' measurements (length and width) and yield thus indicating that the selection of parents and direction of crosses is essential for yield maximization (Table 3 ).

Finally, to address the third question (i.e., can we improve the fruit yield under field conditions by various spatial arrangements of maternal and paternal plants?), the observed differences in the studied attributes among the diallel mating crosses and their direction clearly provided the answer to this question. For breeding purposes, it is clearly obvious that hand pollination require the creation of exclusively female flowers, thus involving manual emasculation of the perfect flowers. The results from the present study point toward the adoption of artificial pollination for maximizing fruit and seed productivity; however, this practice is costly prohibitive rendering its adoption unsustainable. To effectively capitalize on the observed differences among the studies yellowhorn fruit shape types namely (1) general and specific compatibility, (2) male and female propensities, and (3) the detrimental effect of selfing, an open-pollination production mode with spatial fruit shape types arrangement could provide practical way for enhancing production and further improving fruit quality for this species with its known self-incompatibility and late-acting self-incompatibility (LSI). Proper arrangements of maternal and paternal plants have been effectively used to improve fruit production in apples and pears orchards (Delaplane et al. 2010; Way 2006). According to the observed differences among the all possible fruit shape types' matings along with that of the open-pollination, a three alternating rows arrangement utilizing fruit shape types 2,3 , and 5 where each shape type is flanked by the other two types could be a viable commercial production option for yellowhorn seed. Under this arrangement, each fruit shape type will serve as both male (pollen donor) and female (pollen receptor) for the other two; mating within rows (i.e., between different genotypes within a specific fruit shape type) is outcrossing and should not be detrimental and within plant selfing should be inconsequential as demonstrated by the inbreeding depression (Table 2). Furthermore, an alternative strategy that consider grafting of multiple fruit shape types (e.g., fruit shape types 2 , 3 , and 5) on the same rootstock is worth exploring.

\section{Conclusion and perspective}

The cross-pollination experiment demonstrated the intricacies of yellowhorn breeding system and indicated that the selection of appropriate fruit shape-type matings could significantly improve many of the fruit and seed traits. The study aimed at addressing three questions: (1) Does fruit shape affect the fruit yield? (2) Which shape type is best matched with respect to yield aspect? (3) Can we improve the fruit yield under field conditions by various spatial arrangements of maternal and paternal plants? Answers to these questions demonstrated that (1) fruit shape significantly influenced fruit yield, (2) the identification of general and specific combiners for either controlled- or open-pollination, and (3) proposing of a planting spatial arrangement, involving the most productive fruit shape type for enhancing the species' fruit production capabilities.

Acknowledgements The authors are grateful to Feihai Yu, Shiliang Zhou, and Qingyuan Zhou for their advice and constructive reviews. Thanks are extended to Huan Xu, Yunjia Yang, and Quanxi Bi for helping with the field experiment.

Authors' contributions YAE and WBG conceived the original experiment; QW, ZYW, and YZH collected and analyzed data. QW wrote main part of the manuscript. YAE and WBG edited, all authors have read, and approved the final version of the manuscript.Funding informationThis work was funded by State Bureau of Forestry Science and Technology Development Center grant (no. 2014009). QW was also supported by Chinese Scholarship Council (CSC).

Compliance with ethical standards

Conflict of interest The authors declare that they have no conflict of interest.

Data archiving statement The data supporting this study are available in the Dryad Digital Repository, doi: (doi will be provided after the formal acceptance of this MS).

Open Access This article is distributed under the terms of the Creative Commons Attribution 4.0 International License (http:// creativecommons.org/licenses/by/4.0/), which permits unrestricted use, 
distribution, and reproduction in any medium, provided you give appropriate credit to the original author(s) and the source, provide a link to the Creative Commons license, and indicate if changes were made.

\section{References}

Bartlewicz J, Vandepitte K, Jacquemyn H, Honnay O (2015) Population genetic diversity of the clonal self-incompatible herbaceous plant Linaria vulgaris along an urbanization gradient. Bot J Linn Soc 116:603-613

Bateman AJ (1948) Intera-sexual selkection in Drosophila. Heredity 2: 349-368

Bawa KS, Webb C, Tuttle A (1982) The adaptive significance of monoecism in Cnidoscolus urens (L.) Arthur (Euphorbiaceae). Bot J Linn Soc 85:213-223

Bedhomme S, Bernasconi G, Koene JM, Lankinen Å, Arathi HS, Michiels NK, Anthes N (2009) How does breeding system variation modulate sexual antagonism? Biol Lett 5:717-720. https://doi.org/ 10.1098/rsbl.2009.0401

Canli F, Pektas M (2015) Improving fruit size and quality of low yielding and small fruited pear cultivars with benzyladenine and gibberellin applications. Eur J Hortic Sci 80:103-108

Cantín CM, Gogorcena Y, Moreno MÁ (2010) Phenotypic diversity and relationships of fruit quality traits in peach and nectarine [Prunus persica (L.) Batsch] breeding progenies. Euphytica 171:211-226

Chai C-S, Qi J, Xue R, Lu J, Wang Z-t, Wang S-Y (2013) Development history of Xanthoceras sorbifolia artificial plantation and its resources quantity. For Res Manag 26:181-191

Chan P-K, Mak E (2006) A novel compound isolated from Xanthoceras sorbifolia inhibits ovarian cancer: identification of diangeloyl groups in saponin essential for anti-tumor activity. Cancer Res 66:452-453

Charlesworth D, Charlesworth B (1987) Inbreeding depression and its evolutionary consequences. Annu Rev Ecol Syst 18:237-268

Cohen D, Dukas R (1990) The optimal number of female flowers and the fruits-to-flowers ratio in plants under pollination and resources limitation. Am Nat 135:218-241

Delaplane KS, Thomas PA, McLaurin WJ (2010) Bee pollination of Georgia crop plants. http://hdl.handle.net/10724/12165

Ding M, Ao Y (2008) Research progress on the flowering and fruit set of Xanthoceras sorbifolia Bge. Chin Agric Sci Bull 24:381-385

El-Kassaby YA (1995) Evaluation of the tree-improvement delivery system-factors affecting genetic potential. Tree Physiol 15:777-790

El-Kassaby YA, Cook C (1994) Female reproductive energy and reproductive success in a Douglas-fir seed orchard and its impact on genetic diversity. Silvae Genet 43: 243-245.

El-Kassaby YA, Funda T, Liewlaksaneeyanawin C (2015) Increasing Breeding without Breeding (BwB) efficiency: full- vs. partialpedigree reconstruction in lodgepole pine. SOJ Genet Sci 2:1-6

Fu Y-J, Zu Y-G, Wang L-L, Zhang N-J, Liu W, Li S-M, Zhang S (2008) Determination of fatty acid methyl esters in biodiesel produced from yellow horn oil by LC. Chromatographia 67:9-14

Grandillo S, Ku H, Tanksley S (1999) Identifying the loci responsible for natural variation in fruit size and shape in tomato. Theor Appl Genet 99:978-987

Jordan CY, Connallon T (2014) Sexually antagonistic polymorphism in simultaneous hermaphrodites. Evolution 68:3555-3569

Kirkpatrick LA, Feeney BC (2012) A simple guide to IBM SPSS for version 20.2. Nelson Education.

Liu J, Cong B, Tanksley SD (2003) Generation and analysis of an artificial gene dosage series in tomato to study the mechanisms by which the cloned quantitative trait locus fw2. 2 controls fruit size. Plant Physiol 132:292-299
Ma CM, Nakamura N, Nawawi A, Hattori M, Cai S (2004) A novel protoilludane sesquiterpene from the wood of Xanthoceras sorbifolia. Chin Chem Lett 15:65-67

Miedaner T, Geiger HH (2015) Biology, genetics, and management of ergot (Claviceps spp.) in rye, sorghum, and pearl millet. Toxins (Basel) 7:659-678. https://doi.org/10.3390/toxins7030659

Qiao X-Y (2009) Methods to enhance fruit set percentage of Xanthoceras sorbifolia Bge. Hebei J For Orchard Res 3:298-300

R Core Team (2013) R: a language and environment for statistical computing. R Foundation for Statistical Computing, Vienna, Austria. URL http://www.R-project.org/

Renner SS (2014) The relative and absolute frequencies of angiosperm sexual systems: dioecy, monoecy, gynodioecy, and an updated online database. Am J Bot 101:1588-1596 http://www.amjbot.org/ content/101/10/1588.short

Runquist RDB, Geber MA, Pickett-Leonard M, Moeller DA (2017) Mating system evolution under strong pollen limitation: evidence of disruptive selection through male and female itness in Clarkia xantiana. Am Nat 189:549-563

Scobie A, Wilcock C (2009) Limited mate availability decreases reproductive success of fragmented populations of Linnaea borealis, a rare, clonal self-incompatible plant. Ann Bot 103:835-846. https:// doi.org/10.1093/aob/mcp007

Selim M (2013) Inheritance of fruit shape index in some botanical varieties of melon, cucumis melo. Egypt J Plant Breed 17:155-168 http://www.egy-j-p-breeding.com/reserachgenerator/uploads/ 1444889380.pdf

Serquen FC, Bacher J, Staub JE (1997) Genetic analysis of yield components in cucumber at low plant density. J Am Soc Hortic Sci 122:522$528 \mathrm{http}: / /$ journal.ashspublications.org/content/122/4/522.short

Stajnko D, Rakun J, Blanke M (2009) Modelling apple fruit yield using image analysis for fruit colour, shape and texture. Eur J Hort Sci 7: 260-267 http://www.jstor.org/stable/24126399

Stephenson A (1992) Regulation of maternal investment in plants. In: Marshal C, Grace J (eds) Fruit and seed production: aspects of development, environmental physiology and ecology. Cambridge University Press, Cambridge, pp 151-171

Tan J, Tao Q, Niu H, Zhang Z, Li D, Gong Z, Weng Y, Li Z (2015) A novel allele of monoecious $(\mathrm{m})$ locus is responsible for elongated fruit shape and perfect flowers in cucumber (Cucumis sativus L.) Theor Appl Genet 128:2483-2493. https://doi.org/10.1007/s00122-015-2603-0

Venable DL, Burquez A (1989) Quantitative genetics of size, shape, lifehistory, and fruit characteristics of the seed-heteromorphic composite Heterosperma pinnatum. I. Variation within and among populations. Evolution 43:113-124 http://www.jstor.org/stable/2409168

Way RD (2006) Pollination and fruit set of fruit crops. http://hdl.handle. net/1813/3296

Young AG, Pickup M (2010) Low S-allele numbers limit mate availability, reduce seed set and skew fitness in small populations of a selfincompatible plant. J Appl Ecol 47:541-548

Zhang S, Hu J, Zhang C-F, Guan Y-J, Zhang Y (2007) Genetic analysis of fruit shape traits at different maturation stages in sponge gourd. J Zhejiang Uni Sci 8:338-344. https://doi.org/10.1631/jzus.2007.B0338

Zhang S, Zu Y-G, Fu Y-J, Luo M, Liu W, Li J, Efferth T (2010) Supercritical carbon dioxide extraction of seed oil from yellow horn (Xanthoceras sorbifolia Bunge.) and its anti-oxidant activity. Bioresour Technol 101:2537-2544

Zhou Q-Y, Fu Y-J (2010) Preliminary studies on the reproductive biology of Xanthoceras sorbifolia. Sci Silvae Sin 46:158-162

Zhou Q-Y, Liu G (2012) The embryology of Xanthoceras sorbifolium and its phylogenetic implications. Plant Syst Evol 298:457-468

Zhou Q-Y, Zheng Y (2015) Comparative de novo transcriptome analysis of fertilized ovules in Xanthoceras sorbifolium uncovered a pool of genes expressed specifically or preferentially in the selfed ovule that are potentially involved in late-acting self-incompatibility. PLoS One 10(10):e0140507 